\title{
Research and Design of Complementary Power Supply System of Solar Energy and Electric Supply in Highway Toll Stations
}

\author{
Yuman Zhang ${ }^{1, ~ a}$, Fuchao Yan ${ }^{1, b}$, Zhuling $\mathrm{Li}^{1, \mathrm{c}}$, Ying Duan ${ }^{1, \mathrm{~d}}$, Junyi Chen ${ }^{1, \mathrm{e}}$ \\ ${ }^{1}$ North China Electric Power University, Beijing, 102200, China
}

Keywords: Highway toll stations, Solar energy, Controller, STC, Single chip

\begin{abstract}
In this paper, a complementary power supply system of solar energy and electric supply controlled by SCM is introduced. It is mainly used for the automatic switching of the solar energy and the electric power supply in the highway toll stations. Through the control of the battery charging circuit, discharge circuit and the power supply switch drive circuit, the system realizes the functions of battery management and system operation control. In this paper, the working principle, hardware configuration, software design and function of the system are discussed in detail. The results show that the system has good functions, high practical value and good application prospect.
\end{abstract}

\section{Introduction}

In the face of the requirements of sustainable development, the development and popularization of renewable energy has become the trend of the times. Solar lighting system often in continuous rainy days, due to lack of battery voltage and the load cannot be lit. In order to solve these problems, this paper establishes a kind of control system of solar energy and electricity complementary switching power supply based on single chip microcomputer. The utility model can make up the problem of unstable solar energy utilization, reduce the cost of developing and utilizing solar energy technology, and simultaneously satisfy the requirements of system reliability and economy.

\section{System Composition}

The system is composed of a collecting device, a controller and an electric device. The utility model can realize the solar energy collection, the battery power supply and the power switch, and is applied to the power supply system of the expressway toll station. 
Collecting Device. The charging circuit collecting device is mainly composed of solar panels and solar energy to the battery components, because the overall circuit design relates to a controller of battery charging, so this section mainly introduces the selection of solar panels and is suitable for the highway toll station placed way. Polycrystalline silicon solar cell and single crystal silicon solar battery life and stability are good. The commonly used single crystal silicon toughened glass and waterproof resin package, so its durable service life can reach 15 years or even 25 years. The service life of the polycrystalline silicon solar cell is shorter than that of the mono-crystalline silicon solar cell. The average conversion efficiency of mono-crystalline silicon solar cells is about $1 \%$ higher than the average conversion efficiency of polycrystalline silicon solar cells. Therefore, the efficiency difference of solar cell modules is not large.

Power Device. Take the highway toll station for example, it involves the use of electrical equipment, including computer, highway railing machine, highway monitoring system, DC inverter, LED lighting and USB as the port of electrical appliances.

\section{Principles and Components of Controller}

Work Principles of Solar Controller. This design switches the solar electric complementary power supply mode through STC89C52 MCU. By using the voltage acquisition circuit, the voltage of the solar battery and the storage battery voltage are collected, and the voltage is divided into high and low level input single-chip microcomputer through the conversion of the A/D module. It judges by the microcontroller and outputs the signal to the battery and the relay to switch the power model of toll stations.

Components of Solar Controller. The controller is mainly composed of 8052 single chip microcomputer (including A/D), voltage sampling circuit and switch driver circuit. Single chip microcomputer 8052 is the core of the controller. The peripheral circuit includes the switch control circuit (C1-C3), and voltage acquisition circuit, drive circuit, work status display. STC89C52 is a kind of $8 \mathrm{~K}$ bytes of FPEROM (Flash Programmable and Erasable Read Only Memory) low voltage, high performance COMOS8 processor. The device uses ATMEL density non-volatile memory 
manufacturing technology manufacturing, and industry standard MCS-51 instruction set and output pin compatible. The solar controller is composed of a charging control circuit, a discharge electric control circuit, a power switching circuit, a battery collecting circuit and a solar battery collecting circuit.

Functions of Solar Controller. The design of controller is mainly used in highway toll station or residential security booth using solar energy and electricity complementary power supply system. According to the actual situation of the solar charging and discharging and battery status, the controller has the following functions: 1 , the real-time voltage of solar battery, automatic switching mode; 2, real-time acquisition of the voltage of the battery, the battery charge and discharge control mode; 3, with anti-charging protection, overcharge and over discharge protection function; 4, support semi power and full power of two kinds of discharge mode; 5 , the battery power shortage, automatic switching power supply system for the city.

\section{System Overall Design}

Design of Hardware Circuit. The hardware circuit design of this system is mainly composed of five modules, including the solar voltage acquisition circuit, the battery charging circuit, the battery voltage acquisition circuit, the battery discharge circuit and the power supply switch drive circuit. The voltage acquisition circuit adopts $5 \mathrm{~V}$ power supply voltage from VCC terminal voltage, the judgment through the two resistor divider after generation relay, when the VCC input signal changes, will drive the relay switch to achieve the switching signal output fluctuations, $5 \mathrm{~V}$ and $0 \mathrm{~V}$. The output signal is transmitted into the microcontroller, the microcontroller for processing according to the input signal, and then the output control signal, when the solar panel voltage is higher than $12 \mathrm{~V}$ and the battery voltage is higher than $9 \mathrm{~V}$, the relay switch to the $5 \mathrm{~V}$ power supply side, high output, while adding the regulator, to ensure the voltage of the relay is not too high judgment and burning device. The voltage acquisition circuit is shown in Figure 1. 


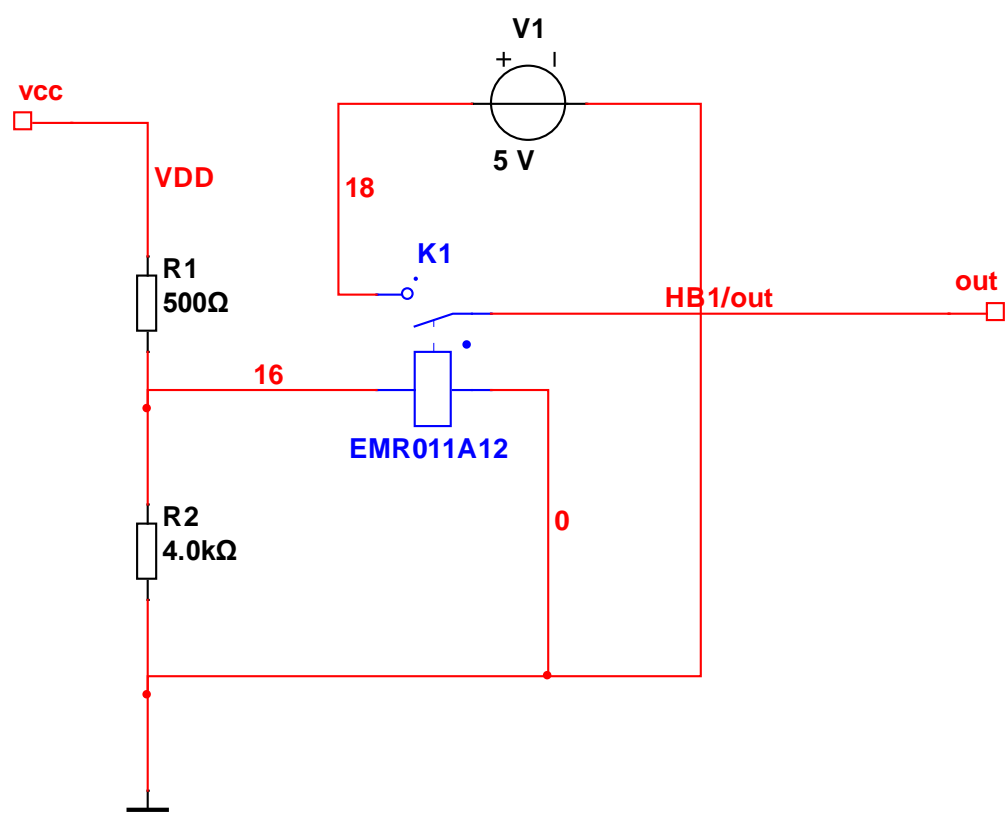

Figure 1. Voltage acquisition circuit

The battery charging circuit is controlled by the PWM1 output signal. The input TVCC is connected with the solar panel, and the output end of the put1 is connected with the storage battery. Among them, the voltage input voltage for solar panels to collect, the output voltage is determined by the PWM1 level: when PWM1 is high, the put1 side is high, the battery; when PWM1 is low, put1 is also low, stop charging the battery. In this circuit, the LED lamp is used to show whether the battery is charging or not. At the same time, the utility model uses the Schottky diode to complete the anti-charge protection. The C1 charging circuit is shown in Figure 2.

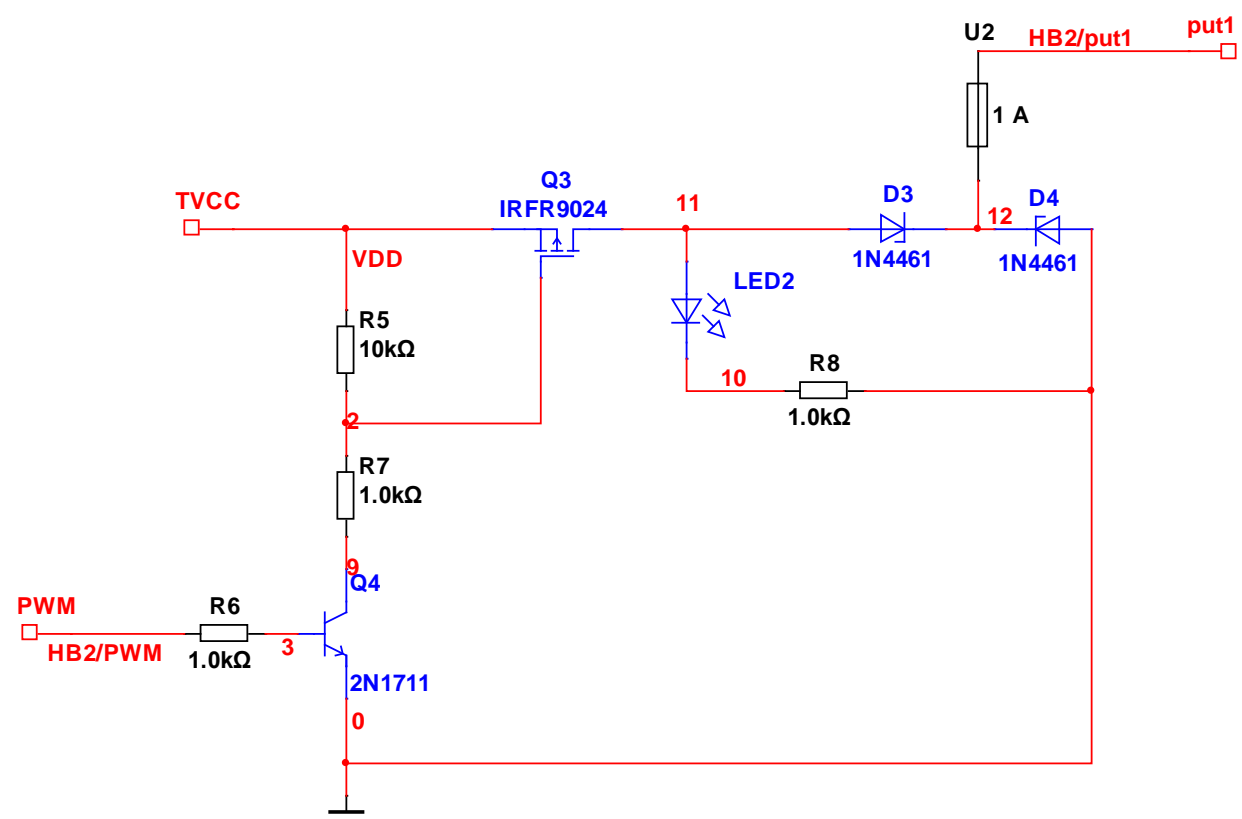

Figure 2. C1 charging circuit 
The battery discharge circuit is controlled by the output of the PWM2 signal. The input end of the VCC is connected with the storage battery, and the output end of the out is connected with the input end of the power supply switch driving circuit of the city. The input voltage of the battery voltage, the output voltage is directly controlled by PWM2 level: when PWM2 is high, the battery is full power discharge mode; when PWM2 is low, half power battery discharge mode. The battery discharge circuit is shown in Figure 3.

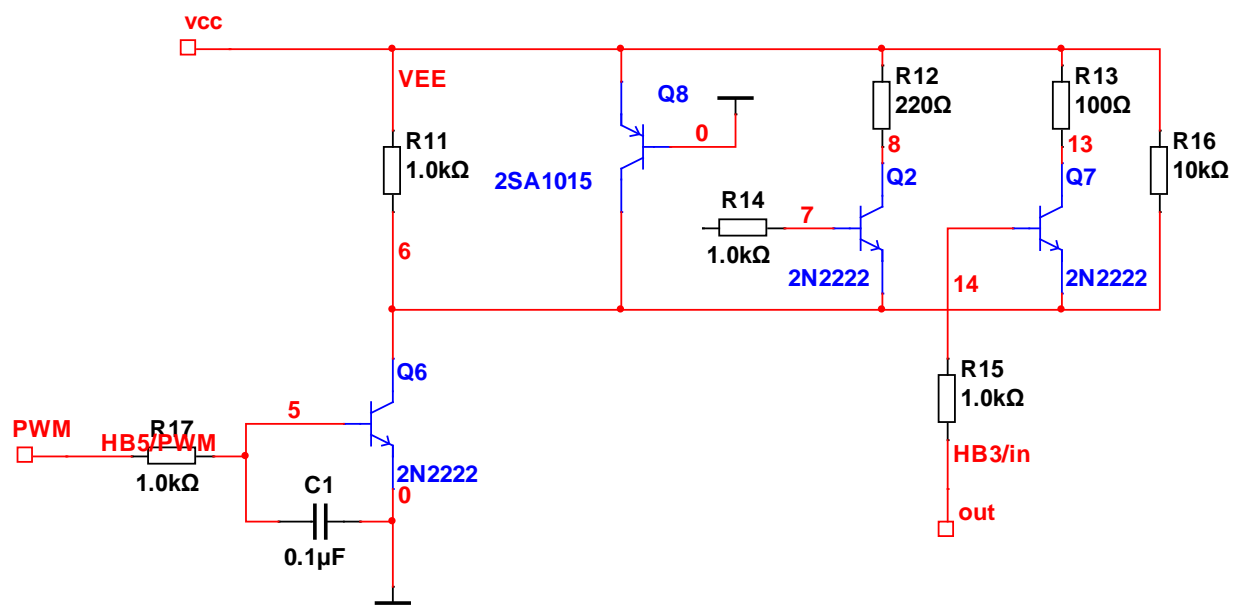

Figure 3. Battery discharge circuit

The control circuit of the power supply switch is controlled by the output signal of PWM3. The input end of the out is connected with the output end of the battery discharge circuit, and the output end of the in is directly connected with an electric device or an inverter to be converted into an alternating current and then connected with an electric appliance. Among them, PWM3 level direct control relay: when PWM3 is high, the switch to a closed access, electricity supply side, namely the power to use electrical power supply; when PWM3 is low, the power supply switch down closed access battery terminal, the battery to use electrical power supply. Thus, the power supply is switched on or off by the switch of the relay, and the power switching process is completed. The switch driving circuit of commercial power supply is shown in Figure 4. 


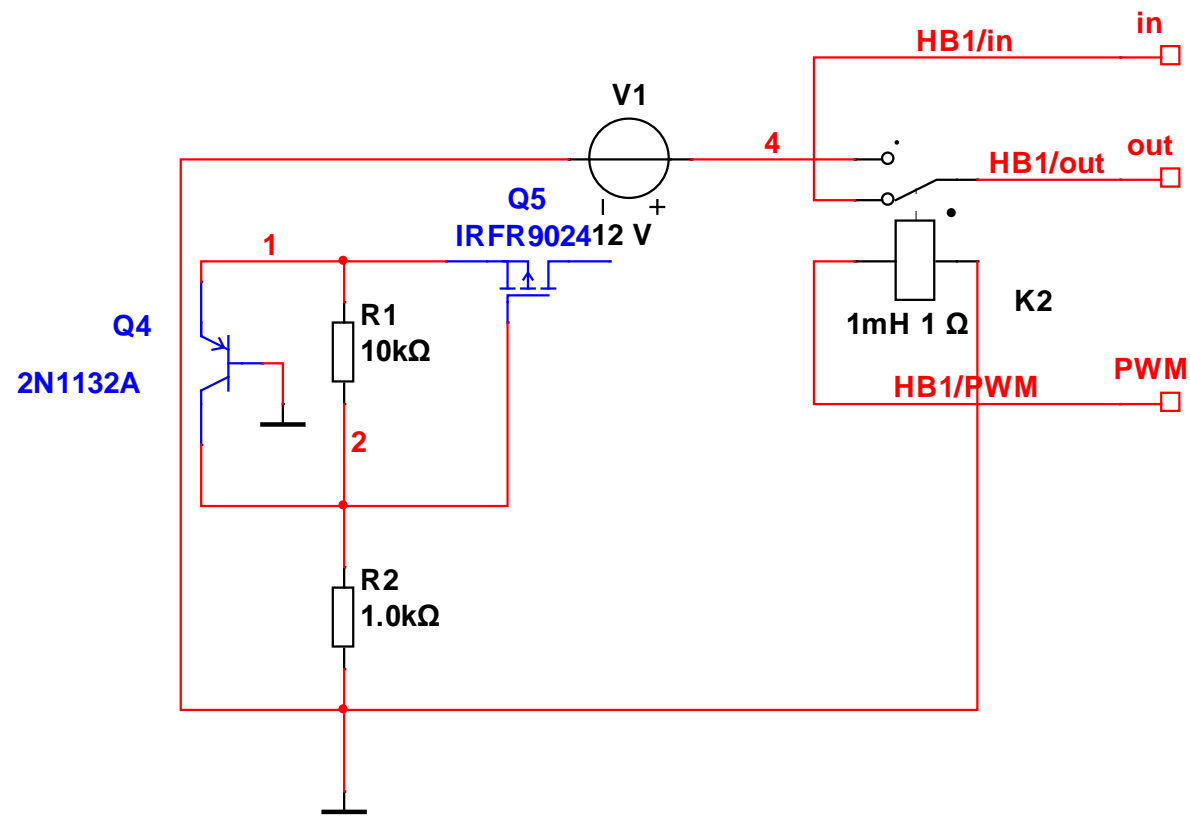

Figure 4. Switch driving circuit of commercial power supply

Design of Software Program. The main circuit of PWM1, PWM2 and PWM3 pulse is given directly by the microcontroller. The fixed frequency is $30 \mathrm{kHZ}$. The program implementation process is as follows. The first parameter initialization of the chip, then the voltage of battery and solar battery voltage sampling, to judge the battery at any interval, if the battery voltage is less than $9 \mathrm{~V}$, the implementation of electric power supply; if the battery voltage is greater than $9 \mathrm{~V}$, and then determine the solar battery voltage at any interval. If the solar battery voltage is greater than $0 \mathrm{~V}$, the battery charging and battery power supply to perform full; if the solar battery voltage is equal to $0 \mathrm{~V}$, the battery charging and does not perform the battery power supply half.

\section{Test}

The function of the controller is tested. During the test, the normal operation of the whole solar control system, in addition to the LED light condition is not stable, interruption, no big problem. In the actual test, the controller is connected with the solar panel, the universal meter and the oscilloscope. Then, the charging test and discharge test are done. 


\section{Conclusion}

Based on the design of the controller based on microcontroller STC89C52 as the main function realization part, the functions of microcontroller and solar electric complementary power supply system are good when the experimental test are done. The system has high practical value and good application prospect. It has theoretical reference value for the popularization and application of the solar power switch control system and the improvement of the power supply system of the expressway toll station. At the same time, the system can be extended to the security booth and more areas and have huge development potential.

\section{References}

[1] MARCHESONI M. High-performance current control techniques for applications to multilevel high-power voltage source inverters [J]. IEEE Transactions on Power Electronics, 1992, 7(1): 189-204.

[2] Wu Libo, Zhao Zhengming, Liu Jianzheng. Intelligent controller for photovoltaic lighting systems [J]. Journal of Tsinghua University (Science and Technology), 2003, 43(9): 1195-1198.

[3] Bi Jinjie, Luo Xiaoshu, Yang Rixing, Zhang Lu. Design of Solar Energy Controller Based on AVR [J]. Modern Electronics Technique, 2009(10): 167-169.

[4] Wang Sicheng, Chen Ziping, Yang Jun, Yu Anye. SOC modeling for lead-acid battery and developments of SOC on-line tester [J]. Acta Energiae Solaris Sinica, 2005, 26(1): 6-13. 